\title{
ANXIETY, DEPRESSION, AND SELF-CARE MANAGEMENT AMONG PATIENTS WITH HYPOTHYROIDISM
}

\author{
NILA KM*, MEKHANA VD, SRUTHI R NAIR \\ Department of Medical Surgical Nursing, Amrita College of Nursing, Amrita University, Kochi, Kerala, India. Email: nilakm19729@aims. \\ amrita.edu
}

Received: 01 July 2017, Revised and Accepted: 26 October 2017

\section{ABSTRACT}

Objective: The objective of the study was to assess anxiety, depression, and self-care management among patients with hypothyroidism.

Methods: A qualitative descriptive study was done among 65 patients who was diagnosed with hypothyroidism, and the data were collected using structured questionnaire to know about self-care management of hypothyroidism and standardized tool (Hamilton rating scale) for assessing anxiety and depression.

Results: The result showed that among 65 subjects, 30 (46.2\%) had good self-care management, only 1 (1\%) had excellent self-care management, $46.1 \%$ had severe anxiety, whereas $4.6 \%$ subjects had severe depression. There was a positive association between anxiety and depression with selfcare management.

Conclusion: Hypothyroidism is now becoming more prevalent in the Indian population. From the results of the study, it is obvious that patients with hypothyroidism are at increased risk of anxiety and depression. Self-care management decreases with an increase in anxiety and depression. Hence, proper management is necessary to reduce the deleterious effect of hypothyroidism on physical as well as mental health.

Keywords: Self-care management, Anxiety, Depression, Hypothyroidism.

(C) 2018 The Authors. Published by Innovare Academic Sciences Pvt Ltd. This is an open access article under the CC BY license (http://creativecommons. org/licenses/by/4. 0/) DOI: http://dx.doi.org/10.22159/ajpcr.2018.v11i1.21074

\section{INTRODUCTION}

Thyroid gland is one of the most significant gland in our body. It releases hormones, and the main function of the gland is to take iodine found in many foods and to convert it into thyroid hormones thyroxine [T4] and triiodothyronine [T3]. When the gland does not produce enough thyroid hormone, it is called "hypothyroidism" or unreactive thyroid. Hypothyroidism is a clinical syndrome due to deficiency of thyroid hormone. Thyroid hormone is responsible for maintaining the brain hemostasis and helps in central nervous system global development. Hypothyroidism, due to a deficiency of circulating thyroid hormones, is a disease with wide-ranging symptoms and signs affecting many systems and presenting to various specialists. It can cause many symptoms such as depression, anxious mood, weight gain, and poor ability to concentrate. Subclinical hypothyroidism $(\mathrm{SCH})$ is a common endocrine disorder presented by mildly elevated thyroid-stimulating hormone above the reference range along with a normal concentration of free thyroxine (FT4) and triiodothyronine (T3).

Thyroid dysfunction has been recognized to cause significant manifestations in mental health. The most common psychiatric symptoms related to hypothyroidism are depression and cognitive dysfunction. They lead to disturbance in emotions and cognition. Both increase and decrease in thyroid function can cause mood abnormalities. Vice versa, depression can also go hand in hand with subtle thyroid dysfunction. Hypothyroidism impacts certain aspects of cognitive functioning and mood. More severe hypothyroidism can mimic melancholic depression and dementia. Thus cause reduction in health-related quality of life. High prevalence of moderate to high level depression, anxiety cause increased stress response and it triggers a cascade which producing a series of changes in human vital physiological functions such as blood pressure, respiratory rate and heart rate which was significantly higher. Although the results are inconsistent, data to suggest that the neuropsychiatric symptoms tend to improve with treatment for both overt hypothyroidism and SCH and normalization to an euthyroid state.

In case of acute hypothyroidism, anxiety disorders occur in about 30\%$40 \%$ of patients. Patients with SCH can present with anxiety, irritability, poor concentration, and slow information process in comparison to the normal subject.

A study to assess the prevalence of anxiety depression and self-care management among patients with hypothyroidism is conducted in selected wards and OPDs of AIMS, Kochi, Kerala, India, with the objectives to find the level of anxiety, level of depression, and selfcare management of patients with hypothyroidism and to associate depression, anxiety, and self-care management of selected demographic variables, depression, anxiety with self-care management, and depression with anxiety. Assumptions were hypothyroidism impacts on certain aspects of cognitive functioning and mood, and efficient management of hypothyroidism will help to decrease thyroid related morbidity and mortality.

\section{METHODS}

Quantitative approach with the descriptive design was used for the study. Patients who diagnosed with hypothyroidism and who were available during data collection were included in the study. The sample size was 65 and was selected by purposive sampling technique. Endocrinology OPD and selected wards of Amrita Institute of medical science and research Center, Kochi, were the research setting.

Data collection instruments were semi-structured questionnaire to assess self-care management, which has two sections. Section A contains sociodemographic data, which include the age, gender, religion, educational status, occupation, marital status, history of illness of hypothyroidism, and family history of patients with hypothyroidism. 
Section B consists of 15 questions which include clinical parameters, physical activity, dietary pattern, and medication. Hamilton rating scale was used for assessing anxiety and depression. Tool was assessed by 5 experts from the Department of Medical Surgical Nursing and Head of the Department of Endocrinology of AIMS, Kochi. The reliability was assessed using the split-half method, $r=0.86$. A pilot study was conducted to find the feasibility of the study. The ethical certificate is obtained from the research committee of Amrita College of Nursing and thesis review committee on AIMS, Kochi. Permission was obtained from the Head of Department of Endocrinology of AIMS, Kochi. The purpose of the study was explained and informed consent was obtained from participants before conducting the study.

\section{RESULTS AND DISCUSSION}

Data obtained were analyzed using descriptive and inferential statistics based on study objective. The sociodemographic characteristics of subjects presented in Table 1 suggested that, among 65 subjects of hypothyroidism, $34(52.30 \%)$ of subjects were under the age group of $\leq 40$ and $31(47.69 \%)$ subjects were under the age group of $>40$. Most $53(81.5 \%)$ resides in an urban community, and $12(18.5 \%)$ belongs to the rural community. Regarding the education status, degree and above degree were 37 (56.9\%) and below degree was 28 (43.07\%). In view of occupational status of subjects, most 36 (55.3\%) were unemployed, and 29 (44.6\%) were employed. Regarding family history, 33 (56.7\%) have hypothyroidism, and 32 (49.2\%) not having a family history.

Fig. 1 shows among 65 subjects, majority of 30 (46\%) was having good self-care management followed by 18 (28\%) of the subject have very good self-care management, and 16 (25\%) have average self-care management. It was found that only $1(1.5 \%)$ have excellent self-care management.

Fig. 2 shows that 28 (43\%) of the subjects have severe anxiety, followed by $16(24.6 \%)$ have moderate level, 12 (18.5\%) have mild, and it was found that only $9(13.8 \%)$ were normal.

Fig. 3 shows that $3(4.6 \%)$ have severe depression, followed by 21 $(32.3 \%)$ was moderately depressed, 29 (44.6\%) have mild depression, and it was found that $12(18.5 \%)$ were normal.

Table 2 depicts the association between anxiety and selected demographic variables of subjects. It shows that there is no significant association between anxiety and selected demographic variables.

Table 3 shows that there is no significant association between depression and selected demographic variables.

Table 4 shows that there is no significant association between self-care management and selected demographic variables.

Table 5 depicts that there is a positive association between depression and self-care management among patients with hypothyroidism ( $p>0.05)$.

Table 6 shows that there is a positive association between anxiety and self-care management among patients with hypothyroidism ( $p>0.05$ ).

Table 7 shows that there is a significant association between anxiety and depression. $(\mathrm{p}>0.05)$.

\section{DISCUSSION}

In this present study, the level of depression was assessed using Hamilton Rating Scale, out of 65 sample, it showed that $3(4.6 \%)$ had severe depression followed by $21(32.3 \%)$ were moderately depressed, 29 (44.6\%) had mild depression, and 12 (18.5\%) were normal.

Similar study was conducted by Rupeesh et al. in Ludhiana in 2009 on psychiatric morbidity among patients with hypothyroidism. The sample size was 100 . The study was concluded as $63 \%$ of patients with hypothyroidism had comorbid depression. Females were showing a high
Table 1: Distribution of demographic variables

\begin{tabular}{ll}
\hline Variables & Frequency (\%) \\
\hline Age & \\
$>40$ & $34(52.2)$ \\
$\leq 40$ & $31(47.3)$ \\
Gender & \\
$\quad$ Female & $64(98.4)$ \\
$\quad$ Male & $1(1.53)$ \\
Occupation & \\
$\quad$ Employed & $29(44.6)$ \\
Unemployed & $36(55.4)$ \\
Area of residence & \\
$\quad$ Urban & $53(81.5)$ \\
Rural & $12(18.5)$ \\
Family history & \\
$\quad$ Yes & $33(50.8)$ \\
$\quad$ No & $32(49.2)$ \\
Duration of illness & \\
$\quad<5$ years & $36(55.4)$ \\
$\geq 5$ years & $29(44.6)$ \\
Educational status & \\
$\quad$ Graduation and above graduation & $28(44.6)$ \\
Below graduation & $37(55.4)$ \\
\hline
\end{tabular}

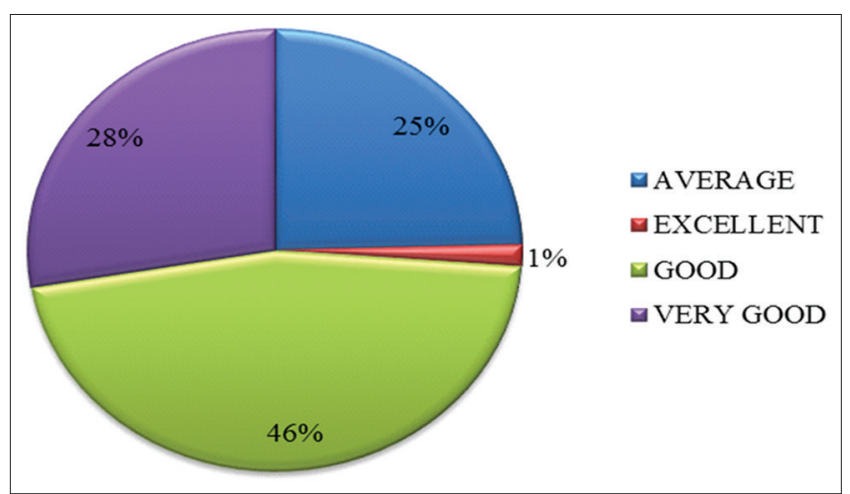

Fig. 1: Percentage of self-care management among patients with hypothyroidism $n=65$

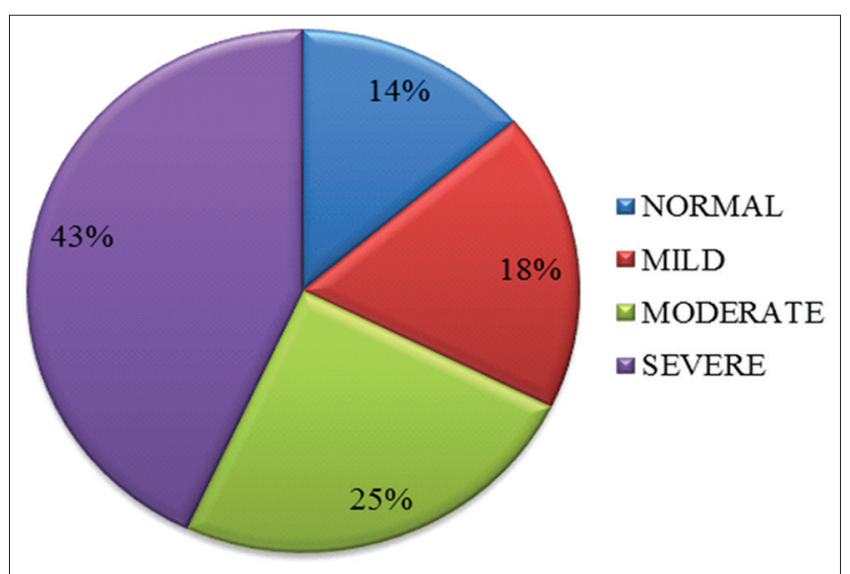

Fig. 2: Level of anxiety among patients with hypothyroidism n=65

percentage of depression as compared to males. This study concluded that level of depression is higher among patients with hypothyroidism.

A case of hypothyroidism-induced recurrent depressive disorder was discussed by Rita et al. of Sree Balaji Medical College in the year 2015. Identification of comorbid physical conditions adding fuel to the disease process has to be identified and treated promptly. This case is reported 
Table 2: Association of anxiety with demographic variables $n=65$

\begin{tabular}{|c|c|c|c|c|c|}
\hline \multirow[t]{2}{*}{ Variables } & \multirow[t]{2}{*}{ Category } & \multicolumn{2}{|c|}{ Anxiety n (\%) } & \multirow[t]{2}{*}{$\chi^{2}$ value } & \multirow[t]{2}{*}{$p$ value } \\
\hline & & Normal & Abnormal & & \\
\hline \multirow[t]{2}{*}{ Age } & $\leq 40(34)$ & $6(17.6)$ & $28(82.3)$ & \multirow[t]{2}{*}{0.863} & \multirow[t]{2}{*}{0.353} \\
\hline & $>40(31)$ & $3(9.7)$ & $28(90.4)$ & & \\
\hline \multirow[t]{2}{*}{ Duration of illness } & $<5(36)$ & $6(16.7)$ & $30(37.1)$ & \multirow[t]{2}{*}{0.538} & \multirow[t]{2}{*}{0.463} \\
\hline & $\geq 5(29)$ & $3(10.3)$ & $26(89.7)$ & & \\
\hline \multirow[t]{2}{*}{ Family history } & No (32) & $6(18.8)$ & $26(81.2)$ & \multirow[t]{2}{*}{1.27} & \multirow[t]{2}{*}{0.260} \\
\hline & Yes (33) & $3(9.1)$ & $30(90.9)$ & & \\
\hline \multirow[t]{2}{*}{ Employed } & Employed (29) & $4(13.8)$ & $25(86.2)$ & \multirow[t]{2}{*}{0.406} & \multirow[t]{2}{*}{0.840} \\
\hline & Unemployed (36) & 5 (13.9) & $27(86.1)$ & & \\
\hline \multirow[t]{2}{*}{ Education } & Below degree (28) & $6(21.4)$ & $22(78.6)$ & \multirow[t]{2}{*}{2.37} & \multirow[t]{2}{*}{0.124} \\
\hline & Degree and above (37) & $3(8.1)$ & $34(91.8)$ & & \\
\hline
\end{tabular}

Table 3: Association of depression and selected demographic variables $n=65$

\begin{tabular}{|c|c|c|c|c|}
\hline \multirow[t]{2}{*}{ Variables } & \multirow[t]{2}{*}{ Category } & \multicolumn{2}{|c|}{ Depression n (\%) } & \multirow[t]{2}{*}{$\chi^{2}$ value } \\
\hline & & Normal & Abnormal & \\
\hline Age & $\leq 40(34)$ & $6(17.6)$ & $28(82.4)$ & 0.863 \\
\hline \multirow[t]{2}{*}{ Duration of illness } & $<5(36)$ & $6(16.7)$ & $30(83.4)$ & \multirow[t]{2}{*}{0.173} \\
\hline & $\geq 5(29)$ & $6(20.7)$ & $23(79.3)$ & \\
\hline \multirow[t]{2}{*}{ Family history } & Yes (33) & $6(18.2)$ & $27(81.9)$ & \multirow[t]{2}{*}{0.348} \\
\hline & No (32) & $6(18.8)$ & $26(81.3)$ & \\
\hline \multirow[t]{2}{*}{ Employed } & Employed (29) & $5(17.2)$ & $24(82.8)$ & \multirow[t]{2}{*}{0.518} \\
\hline & Unemployed (36) & $7(19.4)$ & $29(80.5)$ & \\
\hline \multirow[t]{2}{*}{ Education } & Below degree (28) & $7(25.0)$ & $21(74.9)$ & \multirow[t]{2}{*}{1.40} \\
\hline & Degree and above (37) & $5(13.5)$ & $32(86.5)$ & \\
\hline
\end{tabular}

Table 4: Association between self-care management and selected demographic variables $n=65$

\begin{tabular}{|c|c|c|c|c|c|}
\hline \multirow[t]{2}{*}{ Variables } & \multirow[t]{2}{*}{ Category } & \multicolumn{2}{|l|}{ SCM n (\%) } & \multirow[t]{2}{*}{$\chi^{2}$ value } & \multirow[t]{2}{*}{$p$ value } \\
\hline & & Average and good & Very good and excellent & & \\
\hline \multirow[t]{2}{*}{ Age } & $\leq 40(34)$ & $24(70.6)$ & $10(29.4)$ & 0.113 & 0.973 \\
\hline & $>40(31)$ & $22(71.0)$ & $9(29.0)$ & & \\
\hline \multirow[t]{2}{*}{ Duration of illness } & $<5(36)$ & $25(69.4)$ & $11(30.6)$ & 0.685 & 0.793 \\
\hline & $\geq 5$ (29) & $21(72.4)$ & $8(27.6)$ & & \\
\hline \multirow[t]{2}{*}{ Family history } & No (32) & $23(71.9)$ & 9 (28.s1) & 0.373 & 0.847 \\
\hline & Yes (33) & $23(69.7)$ & $10(30.3)$ & & \\
\hline \multirow[t]{2}{*}{ Employed } & Employed (29) & $22(75.9)$ & $7(24.1)$ & 0.657 & 0.418 \\
\hline & Unemployed (36) & $24(66.7)$ & $12(33.3)$ & & \\
\hline \multirow[t]{2}{*}{ Education } & Below degree (28) & $18(64.3)$ & $10(37.7)$ & 1 & 0.319 \\
\hline & Degree and above (37) & $28(75.7)$ & $9(24.3)$ & & \\
\hline
\end{tabular}

Table 5: Association between depression and self-care management $n=65$

\begin{tabular}{llllll}
\hline \multirow{2}{*}{ Variables } & \multicolumn{2}{l}{ Depression n (\%) } & & \multicolumn{2}{c}{ p value } \\
\cline { 2 - 6 } & Normal & Mild & Moderate & Severe \\
\hline Self-care management & $12(18.5)$ & $29(44.6)$ & $21(32.3)$ & $3(4.6)$ & 0.014 \\
\hline
\end{tabular}

to show the significance of undetected hypothyroidism in a patient with recurrent depressive disorder.

This case reported the significance of hypothyroidism-induced mood disorders, especially in females.

In this present study, the level of anxiety was assessed using Hamilton rating scale, of 65 subjects, 28 (46.1\%) had severe anxiety, followed by $16(24.6 \%)$ had moderate level, $12(18.5 \%)$ had mild, and it was found that only $9(13.8 \%)$ were normal.

A similar study was conducted by Zainil and Kaur A in 2003 on the level of anxiety among patients with hypothyroidism. The sample size was 160 , and the result was the current prevalence of $9.4 \%$ for major depressive disorder (MDD) and 22.5\% for anxiety disorder (AD). Lifetime prevalence was $\mathbf{1 7 . 5 \%}$ for MDD and $27.5 \%$ for AD. Panic disorder was the most common type of AD (16.9\%), followed by generalized $\mathrm{AD}(11.3 \%)$, social phobia (4.4\%), agoraphobia (2.5\%), and obsessive-compulsive disorder (1.9\%). The prevalence of MDD and $\mathrm{AD}$ among patients with thyroid disorders should be recognized. In addition, patients with MDD and AD had poorer quality of life.

In this present study, the self-care management was assessed using a semi-structured questionnaire, and it was found that, of 65 samples, majority (46\%) were having good self-care management, followed by $28 \%$ of subjects had very good self-care management and $25 \%$ had 
Table 6: Association between anxiety and self-care management $n=65$

\begin{tabular}{llllll}
\hline \multirow{2}{*}{ Variables } & \multicolumn{2}{l}{ Anxiety n (\%) } & & \multicolumn{2}{c}{ p value } \\
\cline { 2 - 5 } & Normal & Mild & Moderate & Severe & \\
\hline Self-care management & $9(13.8)$ & $12(18.5)$ & $16(24.6)$ & $28(43.1)$ & 0.020 \\
\hline
\end{tabular}

Table 7: Association between anxiety and depression $n=65$

\begin{tabular}{llllll}
\hline \multirow{2}{*}{ Variables } & \multicolumn{2}{l}{ Depression n (\%) } & \multicolumn{2}{c}{ p value } \\
\cline { 2 - 6 } & Normal & Mild & Moderate & Severe & \\
\hline Anxiety & $12(18.5)$ & $29(44.6)$ & $21(32.3)$ & $3(4.6)$ & 0.010 \\
\hline
\end{tabular}

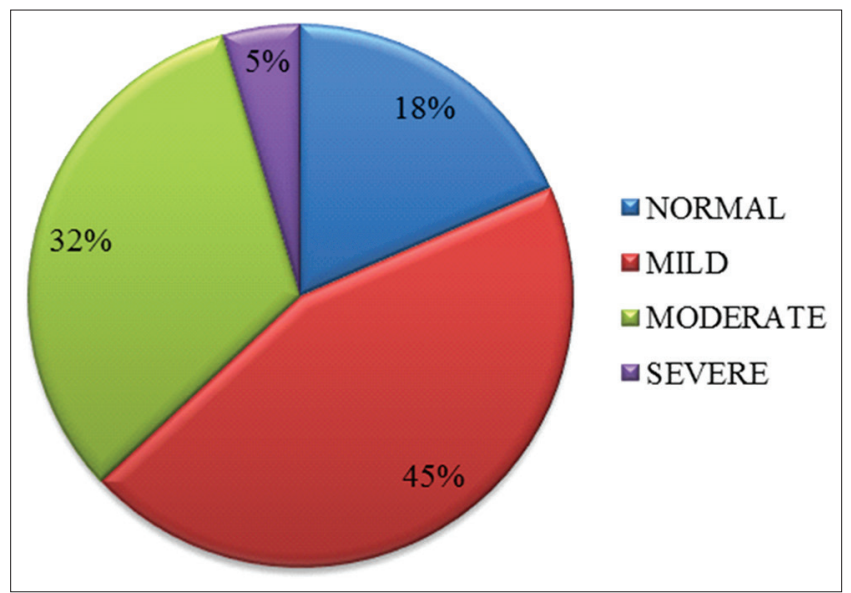

Fig. 3: Level of depression among hypothyroid patient $n=65$

average self-care management. It was found that only $1 \%$ had excellent self-care management.

Another study conducted by Shaileh $e t a l$. on assessment and knowledge regarding thyroid disorder among 250 sample. In the study, $29.2 \%$ of females do not heard the word "thyroid," $48.8 \%$ if females had excessive sensitivity to heat or cold, $25.2 \%$ of females had constipation/diarrhea from long time, $61.2 \%$ of females had joint or muscle pain/weakness, $69.6 \%$ of females had anxiety/depression/mood swing, $39.6 \%$ of females had menstrual irregularity, $82.4 \%$ of females had problem of hair loss/skin changes, and $18.67 \%$ of females had trouble in getting pregnant/repeated miscarriages/stillbirth. Only $49.20 \%$ of females knew about hyperthyroidism and hypothyroidism, $25.2 \%$ of females have undergone the thyroid screening test, and $55.2 \%$ of females thought that thyroid disorders could be cured using alternative medicine.

In this present study, there is no association between anxiety, depression, and self-care management among selected demographic variables, but there is a positive association between anxiety and self-care management, $p=0.020(>0.05)$, and also, there is a positive association between depression and self-care management, $p=0.014(>0.05)$.

A similar study was conducted by Anee E, Innherred hospital, Norway, in 2002 with the aim to examine the association between depression, anxiety, and thyroid dysfunction. The result showed that the group with biochemical hypothyroidism had a significantly lower risk for depression and anxiety compared with the reference group with normal thyroid function. SCH and latent and overt biochemical hyperthyroidism were not risk factors for depression or anxiety. When individuals with former known thyroid disease were excluded from the analyses, the results were essentially identical, but this group had an increased risk of both anxiety and depression, independent of thyroid function. The study was concluded, as in this large, unselected population, we found no statistical association between thyroid dysfunction and the presence of depression or AD. A study conducted by Valeria CB, Joao R H, Lauraws SC conducted a study on subclinical hypothyroidism increased risk of depression in elderly and revealed that subclinical hypothyroidism increases the risk for depression and they emphasize the importance of thyroid screening tests in the elderly.

\section{CONCLUSION}

From the results of the study, it is obvious that patients with hypothyroidism are at increased risk of anxiety and depression. Selfcare management decreases with an increase in anxiety and depression. Hence, proper management is necessary to reduce the deleterious effect of hypothyroidism on physical as well as mental health.

\section{REFERENCES}

1. Rita JA, Nambi S. A case of hypothyroidism induced recurrent depressive disorder. Int J Pharm Pharm Sci 2015;11:398.

2. Abhilash T, Dubey SK, Samanta MK, Alex A, Jose SP. Assessment of psychological stressors of depression and anxiety using depression anxiety stress scale-21 in South Indian healthy volunteers. Int J Pharm Pharm Sci 2016;8:288-95

3. Patil N, Rao K, Balaji O, Naaz H, Baiju G, Naik A, et al. Myxedema madness: An intriguing case of depression in hypothyroidism. Asian $\mathrm{J}$ Pharma Clin Res 2016;10:8-9.

4. Gupta G, Sharma P, Kumar P, Sharma R. Cardiovascular risk in patients with mild to severe subclinical hypothyroidism. Asian J Pharm Clin Res 2016;9:183-5

5. Menon B. Hypothyroidism and bipolar affective disorder: Is there a connection? Indian J Psychol Med 2014;36:125-8.

6. Jayakumar RV. Hypothyroidism. J Indian Med Assoc 2006;104:557-62.

7. Reuters VS, Almeida Cde P, Teixeira Pde F, Vigário Pdos S, Ferreira MM, Castro CL, et al. Effects of subclinical hypothyroidism treatment on psychiatric symptoms, muscular complaints, and quality of life. Arq Bras Endocrinol Metabol 2012;56:128-36.

8. Rupeesh C, Sandeep C, Manikanth S, Aravind S. Psychartic morbidity among hypothyroid patients. Delhi Psychartic J 2014;17:767-41.

9. Zainil N, Kaur A. Level of anxiety among hypothyroid patients. J Eur Psychiatry 2010;25:527.

10. Shaileh R, Suraj S, Khalri AK. Assessment and knowledge regarding thyroid disorder. Indian J Endocrinol Metab 2012;109:21-16.

11. Anne E. Association between anxiety, depression and thyroid dysfunction. Acta Psychiatr Scand 2002;106:27-3.

12. Rajiv R. Thyroid dysfunction and psychiatric disorder. Indian J Med Res 2013;138:888-93.

13. Canaris GJ, Manowitz NR, Mayor G, Ridgway EC. The Colorado thyroid disease prevalence study. Arch Intern Med 2000;160:526-34.

14. Mirella P, Sami T. The link between depression and hypothyroidism. J Thyroid Res 2012;10:5-12.

15. Valeria CB, Joao RH, Lauraws SC. Subclinical hypothyroidism increased risk of depression in elderly. Arch Gerontol Geriatr $2007 ; 44: 27-8$ 